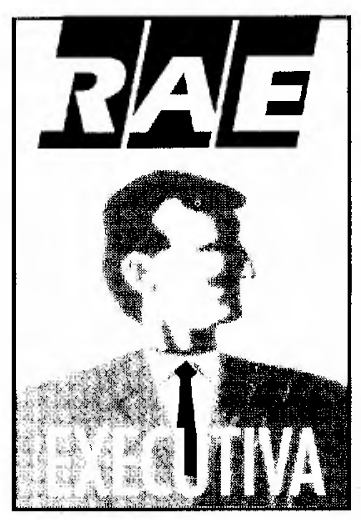

\title{
ORGANIZAÇÃO: UM ESPAÇO DE NEGOCIAÇÃO
}

*Maria Ester de Freitas

Organizações são sistemas políticos onde o comportamento de negociação é, atualmente, uma condição indispensável de sobrevivência.

Organizations are political systems where the negotiation behavior is nowadays an indispensable condition of survival.

\section{PALAVRAS-CHAVE}

Poderorganizacional, confilitos organizacionais, negociação, comportamento de negociação.

\section{KEY WORDS:}

Organizational power, organizational conflicts, negotiation, negotiation behavior.
"Professora do Departamento de Administração Geral e Re cursos Humanos da EAESP/ FGV.
É comum, nos dias de hoje, verificarmos que as empresas, quando traçam perfis para seus executivos, incluem, entre outros requisitos, habilidades comunicativas e de negociação. Ora, ser comunicativo e negociador são traços permanentes do homem. Negociar é uma atividade cotidiana.

Por que, então, as empresas colocam tanta ênfase nesse aspecto atualmente? Uma das pro-

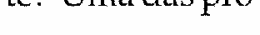

váveis razões está no fato de que as organizações modernas já não podem mais lidar com seus conflitos usando apenas o rigor da autoridade.

À medida que as sociedades se tornam mais abertas; o poder, mais questionável as pessoas, mais reivindicativas, a participação nas decisöes passa a ser considerada como um direito nāo 
1. PRUITT, D. G. Negotiation behavior. New York: Academic Press, 1981.

2. Idem, ibidem. só dos cidadãos, mas também dos membros organizacionais.

Temos ainda o fato de que a especialização técnica, anteriormente supervalorizada, está sendo rediscutida como sendo insuficiente para dar conta da complexidade organizacional. Nesse contexto, a busca de profissionais mais generalistas, mais flexíveis, mais ágeis e com habilidades diversificadas se impõe como uma necessidade, num mundo de mudanças tão aceleradas como o atual.

O modelo do indivíduo competente, porém isolado em seu setor ${ }_{d}$ abre espaço para a equipe multidisciplinar. A reengenharia traduz um novo tipo de estrutura organizacional e, portanto, de padrões diferentes de relações. Os níveis hierárquicos são reduzidos verticalmente e unidades de coordenação são criadas horizontalmente. O reagrupamento de cargos, funções e pessoas para desenvolvimento de produtos e projetos revaloriza o grupo-tarefa e o trabalho coletivo, resultante de um repertório diversificado de conhecimentos e habilidades.

Considerando esse quadro e com ele, a elevação do potencial de conflitos, a capacidade de negociar é vista, não apenas como bem-vinda, mas como imprescindível.

Mas, o que é negociar?

"É uma forma de tomar decisão em que duas ou mais partes conversam entre si num esforço de resolver os seus interesses opostos. Elas expressam as suas demandas contraditórias e se movem em direção a um acordo, através de um processo de fazer concessões e buscar novas alternativas, que ofereçam maiores beneficios mútuos." 1

O processo de negociação pode ser visto como uma forma de conflito social, uma vez que envolve a defesa de interesses opostos, mas também pode ser considerado como uma maneira de resolução de conflitos, dado que as raízes do conflito estão sendo expostas/analisadas e alternativas estão sendo buscadas/viabilizadas.

De acordo com Pruitt ${ }^{2}$, as funçôes da negociação podem ser sumarizadas em:

desenvolver acordos específicos, ou seja, determinar como as pessoas devem se comportar em certas situações, estabelecer procedimentos e fortalecer o rela- cionamento das partes envolvidas no processo;

desenvolver políticas de longo prazo sobre papéis, obrigações e privilégios. Um acordo sobre políticas gerais terá implicações sobre as múltiplas decisões específicas;

mediar a mudança social que ocorre com a falência de estruturas e padrões tradicionais, resultante da alteração das circunstâncias, modificação das necessidades e transformação das relações entre membros e grupos organizacionais. Nesse sentido, podemos entender melhor a mudança na consideração do papel dos sindicatos brasileiros, isto é, a passagem do vilão/agitador/fazedor de greves para um interlocutor, que não pode mais ser ignorado no processo decisório das organizações, inclusive o Estado.

Como um ritual, o processo de negociação é uma atividade planejada, que envolve a definição de algumas fases, procedimentos e atores específicos. Trata-se de um processo dinâmico, onde cada parte agrega novas informações, altera expectativas e modifica comportamentos. E isto é verdadeiro seja no espaço da família, nas relações amorosas ou de trabalho.

Antes de iniciar uma negociação, cada ator reúne informações relevantes sobre a outra parte e sobre si, faz um diagnóstico da situação dos envolvidos, define o seu representante e os limites de sua autoridade, estabelece os pontos passíveis de serem negociados e aqueles que devem ser mantidos em qualquer resultado, assim como algumas estratégias de ação.

Convém relembrarmos que o poder se manifesta de forma relativa, que as partes estão sempre trabalhando com informações incompletas, que a percepção dos parceiros/adversários tem uma grande influência no processo, que ambas as partes estão avaliando sempre a possibilidade de fazer alianças, que o poder de sobrevivência e de incentivos de cada parte está sempre sendo alterado e reavaliado, que a coerção é parte integral do processo e uma estratégia que pode dificultar o relacionamento entre as partes no futuro e que a confiança entre as partes, apesar de difícil, é construída principalmente pelo 
comportamento durante o processo, ou seja, pela atitude de colaboração para a solução do problema.

Quando duas ou mais partes sentam em torno de uma mesa para negociar, significa que já ocorreram, ainda que de forma preliminar, todas ou algumas dessas condições:

acordo sobre a necessidade de negociar; acordo sobre um conjunto de objetivos e princípios;

acordo sobre algumas regras de conduta;

definição de algumas questões e uma pauta;

aceitaçāo dos interlocutores representantes da outra parte;

acordo sobre a necessidade de se implementar conjuntamente as decisōes resultantes do processo.

À medida que o processo avança, novas informações são geradas, novos comportamentos são expostos, novas estratégias são utilizadas. A reavaliação da situação é uma parte permanente. Limites são expandidos e redefinidos. Se a confiança entre as partes é presente, a possibilidade do uso de táticas como blefes, ameaças ou sabotagem de informações é reduzida. Existe sempre a possibilidade de impasses e rupturas, porém, o relacionamento de confiança traz os adversários de volta à luz de novas alternativas.

Obviamente nem toda negociação termina de maneira madura, pacífica e comprometida com o acordo. O comportamento dos parceiros ao longo do jogo é um fator determinante da qualidade do resultado. Traços de personalidade, como agressividade e hostilidade, podem influir e às vezes até inviabilizar a continuidade do processo. Agressões verbais, chantagem e outras ameaças podem levar uma parte a romper a relação e a recusar-se a fazer acordo, isto é, o conflito manifesto não pode ser resolvido. Se isto ocorre, pode significar que a parte que se retira tem um poder de sobrevivência $e$ incentivos maiores que o outro parceiro havia considerado.

A rigor, podemos afirmar que existem três alternativas de comportamento com relaçà̀o a concessões:

conceder unilateralmente, ou seja, abrir mão dos pontos que pretendia ganhar sem pedir nada em troca. Não raro esse comportamento gera uma sensação da pessoa ter sido explorada ou ter sido incompetente ou de ter tomado uma decisão prematura;

marcar firme a posição e não se afastar dela. Tal atitude será respondida com o revide da outra parte e, assim, um impasse pode se prolongar e o acordo - ou não sairá ou demandará bastante tempo, até que uma das partes comece a ceder;

barganhar com a outra parte de forma a elevar o nível de ganhos mútuos ou a reduzir os prejuízos conjuntos. Não vamos esquecer que reduzir prejuízos é também um objetivo sério a ser negociado. As pessoas têm interesse em ganhar, mas querem garantido aquilo que elas já têm. Não esqueçamos que ganhar é uma questão de grau, o que significa que ceder num momento para garantir uma posiçāo futura é uma alternativa que sempre está em consideração.

A escolha de uma dessas alternativas pode ser modificada ao longo do processo, contudo, a que nos interessa em particular é a de barganhar/negociar.

Dissemos anteriormente que ganhar é uma questão de grau. Nenhuma das partes acredita que conseguirá, ao final do processo, ter todas as suas questōes atendidas. O nível de aspiraçāo inicial, de conquistas que serăo perseguidas e de concessōes que serão feitas mudará ao longo dos trabalhos. É muito comum que cada parte comece com uma pauta extensa e com limites excessivamente altos ou baixos, a depender do que defendem. Por exemplo: um sindicato reivindica $90 \%$ de aumento para a categoria que representa c o patrão, seu interlocutor, oferece $12 \%$. O resultado ficará longe dos dois extremos, pois cada parte terá que avaliar as condiçōes e as argumentações do outro, como outras informações e alternativas surgirão e serão consideradas. Em geral, o acordo firmado entre as partes materializa conquistas em relação à situação anterior à negociação, mas é possível que inabilidades políticas levem a um resultado pior, uma espécie de gol contra. Insistimos na diferença de comportamentos entre os parceiros que têm um relacionamento futuro a preservar e aqueles que se envolvem por uma condição acidental. Nesse último 
caso, é comum uma ridigez e uma intolerância aos pontos de vista do outro muito maiores.

Quanto mais se valoriza a capacidade de negociação, mais comum é encontrarmos nas livrarias best-sellers que sugerem receitas para o sucesso. Verdadeiras máquinas de fazer dinheiro, esses livros com títulos Como ganhar qualquer negociação em dez minutos ou Como ganhar todas sem dar nada em troca prestam um desserviço ao leitor, seja ele executivo ou não.

Quando negociar é parte do trabalho diário e envolve pessoas, além de dinheiro, a banalização do assunto é um grande equívoco e às vezes um exercício de máfé. É sempre possivel melhorar a performan$c e$ de um negociador sem cair nas armadilhas da simplificação, dos pacotes irresponsáveis e do psicologismo barato.

Ainda que cada negociação seja um processo único, por envolver pessoas, condições, informaçốes, expectativas, níveis de aspirações e habilidades diferentes, alguns pontos merecem atenção especial e auxiliam na qualidade da decisão que ć acordada pelas partes.

Imagine a situação: um casal decide tirar férias. Ela quer ir para o campo, ele, para a praia. Nenhum dos dois quer ir sozinho. Quais as alternativas que eles podem considerar? Quais os resultados que devem ser evitados?

Suponha que cada um concede unilateralmente, ou seja, ela, de má-vontade, abre mão do campo ou ele, da praia. $\mathrm{Ou}$, ainda, cada um decide marcar firme a sua posição e tentar convencer o outro, sem considerar-lhe o desejo. Quanto mais um e outro argumentam sobre a praia ou o campo, mais se identifica com a posição assumida e tende a perder de vista que o ponto principal é gozar umas boas férias juntos. Uma situação limite pode levar a um impasse tão grande que, para não prejudicar mais ainda o relacionamento, o casal decide não tirar férias. Ou seja, os dois saem perdendo.

Essa não é uma situação tão difícil de ocorrer no dia-a-dia. Quantos casos conhecemos onde o desfecho é baseado em "tudo bem, nem eu e nem ele"? Os tribunais e as varas de família estão lotados de processos, onde os filhos não são poupados das situações mais dolorosas e vergonhosas em nome de uma irracionalidade que privilegia o direito do pai ou da mãe, em detrimento dos maiores interessados na questão. Essas situaçōes também ocorrem dentro das empresas, principalmente em assuntos relacionados à mudança de status, como promoções, por exemplo, ou disputa pela aprovação de projetos.

Um ponto que deve ser evitado, sob risco de comprometer o futuro, é o famoso "ou tudo ou nada". Nesse sentido, é importante ter claro que o foco deve ser concentrado na resolução do problema e que as posições podem ser modificadas.

Um outro aspecto, em geral esquecido, é que os negociadores são pessoas e, como tais, têm emoções, elas se agarram a valores, têm diferentes backgrounds e pontos de vista. São vulneráveis, ficam zangadas e

\section{Um acordo é produto da vontade das partes envolvidas, é sinal de um relacionamento maduro e não uma declaração de guerra.}

deprimidas, hostis, frustradas e se ofendem. Tentar separar a pessoa do problema é um exercício árduo, porém necessário, assim como conhecer como essa pessoa reage. Existem, então, dois aspectos: a substância do problema e o relacionamento envolvido. Perceber a situação do outro e se colocar em seu lugar é uma habilidade importantíssima. A visão da outra parte e o entendimento da sua situação (empatia) ajudam na busca de alternativas de solução que sejam possíveis de ser operacionalizadas conjuntamente. Os ganhos podem ser mútuos e fortalecerão o relacionamento $\mathrm{c}$ a confiança entre as partes.

Fazer concessões não é sinal de fraqueza, mas de abertura, de confiança, de comprometimento com a busca de solução. Quando uma parte faz uma concessão, espera, e até exige, uma reciprocidade. Negar essa reciprocidade é entendido como má-vontade, abuso ou exploração, podendo alterar o comportamento do parceiro 
para uma posição mais rígida e intransigente. Uma vez feita uma concessão, é tratada como definitiva, isto é, não é renegociada (não pode ser retirada) naquele momento, o que implica a necessidade de uma análise prévia das suas conseqüências.

Um processo de negociação pode ser emocionalmente muito desgastante. É importante se perceber o momento de stress, além do qual as partes não conseguem mais produzir informações válidas. A ruptura do relacionamento deve ser evitada (exceto quando ela é uma estratégia) e o adiamento das discussões deve ser negociado de forma objetiva. Fazer balanços parciais, refletir sobre o que se produziu até o momento, realinhar os planos, buscar apoios são fases importantes, uma vez que surgem muitos imprevistos.

Um acordo é produto da vontade das partes envolvidas. Não raro ele pode beneficiar mais um lado que o outro. É fundamental que $o$ ator que se considera mais beneficiado pelo acordo não trate a outra parte como derrotada ou perdedora. O respeito deve ser mantido, assim como a boa vontade na implementação e relação futura. Voltamos à questão da confiança e lembramos que confiar é ter a certeza de que o outro lado não explorará intencionalmente a nossa fraqueza ou vulnerabilidade. Um acordo é sinal de um relacionamento maduro e não uma declaração de guerra.

Em toda negociação as partes definem previamente quais os limites além dos quais elas não podem ceder. Esses limites, ou essa posição-limite é chamada bottom line. É necessário definir, antecipadamente, que nada que a outra parte diga ou faça provoque a mudança dessa linha, pois ela é o suporte da sobrevivência e, portanto, inegociável. Aqui, mais uma vez, a questão da confiança entre as partes exerce um importante papel, pois se ela não existe, como saber se o outro está ou não está blefando? Como se respeita um limite no qual não se confia?

É importante termos em mente que o processo de negociação não se encerra tão logo as partes cheguem a um acordo. $\mathrm{O}$ que foi acordado deve ser implantado, afinal uma decisão só tem valor pela ação que provoca. $\mathrm{O}$ acordo não é um papel assinado, mas decisões que serão executadas durante um determinado tempo, o que requer o convencimento de ambas as par- tes de que o melhor, naquelas circunstâncias, é o que foi conseguido. A falta desse convencimento pode fazer com que uma parte não se comprometa com o resultado e boicote (intencionalmente ou pela apatia) a implantação do acordo. Lembramos aqui uma advertência de Maquiavel, sobre ser mais valioso e menos perigoso um adversário declarado, que se posiciona, do que aquele que permanece neutro, ou, na versão brasileira, em cima do muro. O não a favor e nem contra abre - e muito - espaço para agendas secretas.

Ao longo do desenvolvimento de teorias de análise comportamental nas organizações, deparamo-nos com uma série de tipologias, que marcam determinadas épocas. Desde a Hierarquia das Necessidades, de Maslow, muitas contribuiçôes da Psicologia foram agregadas aos estudos organizacionais, especialmente os voltados à questão da liderança.

O Grid Gerencial, de Blake e Mouton, foi adaptado para vários outros tipos de análise, entre eles os de Cultura Organizacional e Administração de Conflitos e Negociação. A busca de uma "padronização" do ser humano e daquele que "vive" nas organizações tem sido uma constante. Conquanto essa tentativa de padronização, se levada ao pé da letra, é falaciosa, a relativização da sua importância e alcance pode traduzir alguma facilidade no entendimento de determinadas características humanas e nos levar a apreender algumas situações organizacionais de maneira mais clara. É nesse sentido que comentaremos o trabalho que Kenneth $W$. Thomas ${ }^{3}$ desenvolveu a partir do Grid. Ele

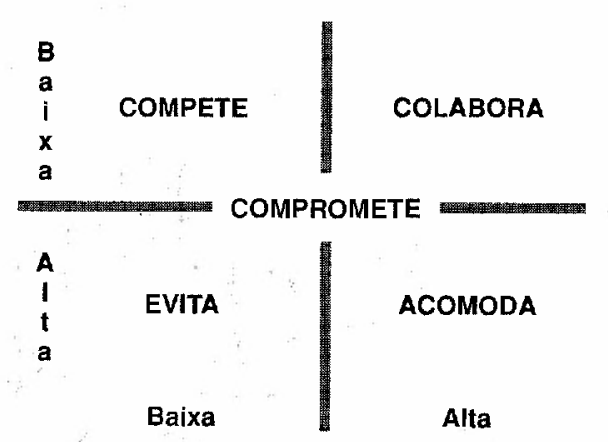

3. THOMAS, K. W. Conflict and conflict management. In: DUNETTE, M. (ed.) Handbook of Industrial and Organizational Psychology. Chicago: Rand Mcnally, 1976. 
propõe uma categorização de estilos comportamentais de negociadores, que se distribui em dois eixos: determinação (usamos essa palavra como uma tradução aproximada para a palavra assertiveness e cooperação), conforme o diagrama 1.

O grau de determinação, ou seja, a energia que é investida na disputa e na busca de solução, é função do poder relativo (grau de sobrevivência, quantidade e qualidade dos incentivos que podem ser oferecidos ao outro lado, potencialidade de fazer alianças, disponibilidade psicológica) de cada parte, bem como da importância que é dada ao objeto do conflito, isto é, os custos e benefícios.

O nível de cooperação é resultado da qualidade do relacionamento entre as partes e do grau de interdependência entre elas ( o nível em que atingir os resultados de uma parte depende da outra parte).

De uma maneira mais simples:

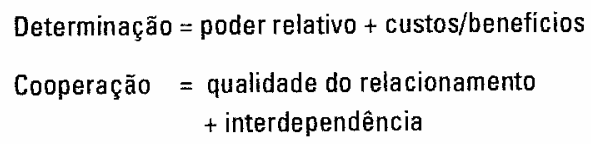

Exemplos dos estilos dispostos na matriz:

quando o que está em jogo é muito importante para A e ele tem poder relativo grande, o grau de determinação será grande, ou seja, tenderá a ter um comportamento competitivo ou colaborador, dependendo da qualidade do relacionamento e da interdependência que tiver com B;

quando o assunto é de pouca monta, os benefícios são menores que os custos da disputa, e o poder relativo é pequeno, a tendência é Evitar ou Acomodar o conflito numa situação de latência, ou seja, ele não se manifestará, pois $A$ não vê como tirar grande proveito da questão. Se entrar com firmeza, pode ainda perder tempo, dinheiro e relações;

quando as duas partes estão mais ou menos no mesmo nível de Determinação e a Cooperação é razoável, porém não boa, a tendência é cada um procurar reduzir as perdas e garantir um ganho não máximo, mas satisfatório (Compromete).

4. AMADO, G., BRASIL, H. V. Organizational behaviors and cultural context: the Brazilian jejtinho. Mimeo, 1990. ceiro/adversário. Às vezes ela é intuitiva, principalmente nas questões mais subjetivas. Essa avaliação perpassa os pontos acima colocados, ou seja, o que ganho ou perco, em que me sustento, qual é meu poder de fogo, até que ponto quero preservar o relacionamento com o outro lado, se algum dia posso precisar ou não do outro lado; enfim, se vale a pena "comprar a briga". É um fato que essa avaliação representa um quadro num determinado momento, por exemplo: considerar que há coisas mais importantes para aplicar as energias e o desgaste não compensaria ou desviaria a atenção de outras questões mais relevantes. É um fato também que toda questão mal-resolvida tende a aparecer no futuro como um antecedente a ser considerado.

Com base nessa tipologia, Kenneth W. Thomas e Ralph H. Kilman desenvolveram um questionário com pares de respostas para determinadas perguntas, que visa a identificar os estilos de negociação predominantes em executivos. Como todo instrumento e toda tipologia, é uma simplificação e um artifício de análise, principalmente se levarmos em conta o fato de que as pessoas não agem sempre da mesma forma, o que significa que num dado momento, uma pessoa pode adotar uma postura extremamente competitiva e no outro, desenvolver uma abordagem colaborativa. No entanto, trata-se de um instrumento interessante por explicitar determinadas características de cada tipo e sugerir a existência de uma abordagem preferencial. Não esqueçamos, contudo, que o ser humano é muito mais do que qualquer modelo (econômico, sociológico, psicológico ou antropológico) possa dar conta e que qualquer catalogação é uma redução das suas potencialidades vistas sob o ângulo que o pesquisador definiu e privilegiou.

Uma outra questão que vem ganhando importância diz respeito à influência dos padrões culturais na postura dos negociadores. Os japoneses, franceses, norte-americanos e brasileiros negociam da mesma forma? É esse o ponto! Um trabalho desenvolvido pelo sociólogo francês Gilles Amado e os pesquisadores da Fundação Dom Cabral, de Belo Horizonte, em 1989, intitulado Organizational behaviors and cultural context: the Brazilian jeitinho ${ }^{4}$, procura investigar as raízes histórico-culturais que dão forma à maneira como os execu- 
tivos brasileiros agem, preferencialmente numa situação de negociação. Utilizando quatro categorias - persuasivo, determinado, empático e sedutor,- o estudo traz comparações com estilos de norte-americanos e europeus.

Os brasileiros aparecem como sendo mais abertos, mais cooperativos, mais receptivos, enquanto o grau de determinação e a capacidade de exercer pressãoé tida como fraca. Dos quatro estilos mencionados, os brasileiros parecem preferir uma abordagem mais empática e sedutora, sendo geralmente pouco objetivos durante o processo. Procuram conciliar, envolver, florear, fazer com que todos ganhem sempre e tendem a evitar confrontos, agressivida de e hostilidade.

Esse trabalho foi utilizado posteriormente pela empresa Marcondes \& Consultores Associados, que desenvolveu uma pesquisa visando a revelar quem é o negociador brasileiro. Os resultados foram publicados em diversos números da revista Tendências do Trabalho.

Um ponto que não deve ser negligenciado diz respeito às condições físicas e psicológicas presentes no processo. O comportamento dos atores é influenciado por variáveis como: o território escolhido (neutro ou não), conforto ambiental, tranqüilidade/interrupçōes, credibilidade e simpatia dos envolvidos, antecedentes do relacionamento ou observações sobre comportamentos anteriores dos envolvidos, preparação dos auxiliares ou assessores, pressão de tempo para fechar o acordo, stress pessoal e profissional.

Todos os parceiros envolvidos num processo de negociação preparam com antecedência suas agendas - explícitas e secretas. Definem com a sua equipe algumas estratégias e táticas que serão usadas e planejam caminhos alternativos. Descreveremos algumas das táticas mais comumente utilizadas.

É comum que os interlocutores façam uma simulação do que pode ocorrer na reunião. Esse exercício, chamado brainstorm- ing, visa a elevar o número de possibilidades de argumentos e contra-argumentos. Algo como "se ele disser isso, eu digo aquilo".

A apresentação da pauta pode ocorrer no estilo cobertor, isto é, mostrando-se as reivindicaçōes de uma vez só, ou via colchete/salame, apresentando e garantindo conquistas ponto por ponto.

A autoridade limitada é, em geral, usada para estabelecer um limite (de prazo, preço, percentual) além ou aquém do qual um lado diz não ter condições de decidir e precisa de aprovação superior. Verdade ou blefe, pode ser usada para ganhar tempo ou forçar o adversário a concordar com esse limite, dispensando novas consultas e perda de tempo. $O$ parceiro que estiver sob menor pressão de tempo tem uma vantagem nesse item.

A abstinência ou o silêncio são rupturas temporárias na comunicação. Não se trata de um simples ato de parar de falar para ouvir. É não dar importância ao argumento que está sendo exposto pelo outro lado. Algo como um simples no comments. Implica uma censura ou desdém, ou apenas ignorar para mudar de assunto.

O blefe é uma espécie de teste à rigidez da posição do outro. Deve ser usado de forma bastante cautelosa, pois pode comprometer a continuidade do processo. Se descoberto, quebra a confiança e pode gerar uma ruptura entre os parceiros se entendido como chantagem (o que é verdade). Traz a marca da intimidação ou tom de ameaça. A ameaça é a estratégia que deixa clara a. intenção de prejudicar. Ela explicita não apenas o castigo, mas também o comportamento que é exigido para que o castigo não seja aplicado.

A surpresa é o uso de informações que um lado não espera que o outro tenha conhecimento ou alianças que tenha conseguido. Causa grande impacto e pode implicar uma reestruturação da agenda, dos argumentos e das táticas usadas até o momento em que ela ocorre.

Acionar o prazo-limite para uma oferta ou uma concessão condicionada significa uma vantagem adicional para quem o utiliza. Força o adversário a repensar sobre
5. TENDÊNCIAS DO TRABALHO, jul. 1987, dez. 1987, jan. 1988 e fev. 1988 . 


\section{A negociação é certamente a alternativa que guarda maiores possibilidades de reduzir o stress que os conflitos organizacionais provocam.}

as conseqüências do Sim e do Não com uma certa urgência. É um recưrso que não deve ser usado a todo instante sób risco de estressar desnecessariamente o outro lado. Ninguém gosta de se sentir acuądo com uma proposta "É pegar ou largar agora".

O balanço é um recurso integrativo que permite às partes reavaliarem o andamento do processo e as conquistas de cada lado. Fm geral, favorece o espírito colaborador e reduz as animosidades. É claro que numa situação em que o poder relativo dos parceiros seja muito desigual pode ter um efeito contrário, no sentido de parecer que o de maior poder está tripudiando com a outra parte.

O bom e o mau sujeitos é um jogo onde os membros da mesma equipe encenam uma discordância entre si. $O$ bon se faz aparecer como mais razoável, enquanto o mau é o radical. Cria uma aparência de dissensão na própria equipe e aliança com o adversário. Se for detectada, pode causar um grande constrangimento e quebra de confiança, por causa da manipulação reconhecida, além da perda de tempo.

\section{CONCLUSÃO}

Consideramos que as organizações são, por natureza, um espaço onde o poder, os conflitos e a convivência negociada são questões rotineiras. Durante muito tempo, a palavra poder causou, nos dirigentes or- ganizacionais, um enorme mal-estar que aumentava ainda mais quando algum pesquisador tinha a ousadia de fazer perguntas diretas sobre o tema. Hoje esse assunto já não é mais um tabu ou pelo menos existe uma abertura maior em relação a ele. As organizações têm aprendido que, para superar dificuldades, énecessário não apenas identificá-las, mas assumi-las. Os conflitos já não são mais tidos como exceções ou algo absolutamente improdutivo. Todos nós, que temós alguma convivência com o univèrso organizacional, sabemos que ele não é um clube de anjos, muito menos de suicidas. As pessoas tềm tentado aprender com as diferenças, procurando conviver e também extrair algo de útil delas.

A valorização atual das habilidades de negociação não significa outra coisa senão que o grupo retomou olugar de honra, que os intercâmbios no mundo do trabalho são. cada vez mais complexos e que as pessoas devem encontrar formas de superar as dificuldades que a convivência forçada traz. A negociação é certamente a alternativa que guarda maiores possibilidades de reduzir o stress que os conflitos organizacionais provocam. Voltamos a insistir que a maneira como o processo se desenvolve é função do que se quer preservar, da confiança na reciprocidade e intenção das partes, da postura percebida e da forma como os argumentos são apresentados. A parte operacional é importante, mas a qualida de dos restaltados a serem alcançados é determinada em larga medida pelos comportamentos assumidos. Nesșe sentido, reforçamos o argumento antes mencionado de não existirem receitas prontas que garantam o sucesso, mas o cuidado com a qualidade das informações e a habilídade em comunicá-las é fundamental. $\square$

\section{2}

\section{BIBUOGRAFIA SUPLEMENTAR}

- FISCHER, R, URY, W. Getting to YES. New York: Penguin Books, 198\%:

- FREUND, I. C. $A$ arte da negociacáo. Saro Paulo Best Seller 1992.

- GLADWIN, T, N. WALTER, I. How multinationals car manage social and political fớcés The Journal of Business stratesy, Summer, 1980.

- MAUBERT, Jean-François. Negnciar. Menn Martins, Porttigal: CETOP, 1991 